\title{
Analisis kebutuhan bahan ajar ipa smp dengan mengeksplisitkan hakikat sains (NOS) dan berpikir kritis topik energi dalam sistem kehidupan
}

\author{
Yayang Prananda, Sri Rahayu*, Safwatun Nida \\ Universitas Negeri Malang, Jl. Semarang No. 5 Malang, Jawa Timur, Indonesia \\ *Penulis korespondensi, Surel: sri.rahayu.fmipa@um.ac.id
}

Paper received: 01-03-2021; revised: 15-03-2021; accepted: 31-03-2021

\begin{abstract}
Science instruction aims to achieving the student's understanding about scientific literacy. However, students' ability of scientific literacy in Indonesia is far from expectation. Integration of scientific literacy aspects can be done into instructional materials. Instructional materials available nowadays not integrating scientific literacy aspects about energy in life system topics. Neccessary science instructional materials on energy in life system topics that potentially to development scientific literacy. This research use a case study of exploratory and results analysis neccessary science instructional materials with expliciting the nature of science and critical thinking on energy in life system topics.
\end{abstract}

Keywords: scientific literacy; science instructional materials; nature of science; critical thinking

\begin{abstract}
Abstrak
Pembelajaran IPA bertujuan untuk mewujudkan siswa yang berliterasi sains. Namun, kemampuan literasi sains siswa Indonesia masih jauh dari harapan. Pengintegrasian aspek literasi sains dapat dilakukan terhadap bahan ajar. Bahan ajar yang ada belum mengintegrasikan aspek literasi sains pada topik energi dalam sistem kehidupan. Sehingga diperlukan bahan ajar IPA topik energi dalam sistem kehidupan yang berpotensi mengembangkan literasi sains. Penelitian ini menggunakan metode studi kasus eksploratis dan menghasilkan analisis kebutuhan bahan ajar IPA dengan mengeksplisitkan hakikat sains (NOS) dan berpikir kritis topik energi dalam sistem kehidupan
\end{abstract}

Kata kunci: literasi sains; bahan ajar IPA; hakikat sains (NOS); berpikir kritis

\section{Pendahuluan}

Proses pembelajaran IPA menekankan pada pemberian pengalaman langsung untuk mengembangkan kompetensi siswa agar mempelajari dan memahami alam sekitar secara ilmiah (Kemendikbud, 2013). Pembelajaran IPA dilaksanakan secara ilmiah untuk menumbuhkan kemampuan berpikir, bekerja dan bersikap ilmiah serta mengkomunikasikannya sebagai aspek penting dalam kecakapan hidup bagi diri siswa (Yuliati, 2008). Pembelajaran IPA tersebut sejalan dengan persepsi IPA oleh ilmuwan yang menyebutkan bahwa IPA sebagai sebuah produk, proses, sikap, dan aplikasi serta tujuan dari pembelajaran IPA. Pembelajaran IPA bertujuan agar siswa mampu memahami materi IPA, menguasai proses IPA, dan menggunakan IPA dalam konteks kehidupan nyata serta mewujudkan siswa yang berliterasi sains (Holbrook \& Rannikmae, 2009; Bell, 2009; Norris \& Philips, 2003; Wenning, 2010; Rahayu, 2014).

Literasi sains didefinisikan sebagai kemampuan untuk menggunakan pengetahuan ilmiah, mengidentifikasi pertanyaan, dan menarik kesimpulan berdasarkan fakta untuk memahami alam semesta dan membuat keputusan dari perubahan yang terjadi karena aktivitas manusia (OECD, 2010). Rahayu (2016) juga menyebutkan bahwa kurikulum sains yang ada saat ini dikritik oleh banyak pihak kurang peka dan kurang tanggap terhadap 
perubahan-perubahan yang terjadi di masyarakat baik lokal, nasional maupun internasional. Rahayu (2014) menyatakan bahwa pemahaman tentang hakikat sains (nature of science, NOS) ditetapkan sebagai salah satu karakteristik yang diharapkan bagi seseorang yang memiliki literasi sains. Sejalan dengan hal tersebut diatas, kemampuan literasi sains siswa dalam mengkonstruk pengetahuan melalui pendekatan ilmiah dengan disertai pengeksplisitan hakikat sains dapat ditingkatkan melalui keterampilan berpikir kritis (Lederman, Lederman, \& Antink, 2013; Mahanani, 2014). Berpikir kritis adalah pemikiran reflektif yang masuk akal yang berfokus pada pengambilan keputusan tentang apa yang harus dipercaya atau dilakukan (Ennis, 2011). Berdasarkan hal tersebut, maka sangatlah penting untuk mengimplementasikan pembelajaran yang secara eksplisit mengintegrasikan aspek-aspek yang dapat meningkatkan literasi sains.

Bahan ajar merupakan salah satu sumber belajar yang penting dalam pelaksanaan pembelajaran di sekolah (Depdiknas, 2008). Bahan ajar dapat memfasilitasi siswa untuk mengkonstruk pengetahuan sesuai langkah pembelajaran dan mengembangkan pengetahuan siswa melalui konten materi yang lebih kontekstual dalam kehidupan sehari-hari (Mahanani, 2014). Oleh karena itu, sangatlah penting untuk mengintegrasikan aspek-aspek literasi sains di dalam bahan ajar, sehingga pembelajaran mengarah pada pengembangan literasi sains. Tujuan penelitian ini adalah untuk mengetahui kebutuhan bahan ajar IPA SMP dengan mengeksplisitkan hakikat sains (NOS) dan berpikir kritis pada topik energi dalam sistem kehidupan.

\section{Metode}

Penelitian ini menggunakan metode penelitian kualitatif dengan jenis studi kasus eksploratis. Ulfatin (2013) menyatakan bahwa studi kasus eksploratis digunakan sebagai penelitian pendahuluan untuk melakukan penelitian berikutnya, misalnya penelitian pengembangan. Studi kasus eksploratis dalam penelitian ini dilakukan untuk mengetahui masalah pembelajaran IPA sebelum mengembangkan bahan ajar IPA.

Pengumpulan data pada penelitian ini dilakukan dengan menggunakan teknik studi literatur. Sumber bacaan dalam penelitian ilmiah tidak hanya dari buku referensi, akan tetapi digunakan sumber-sumber lain seperti jurnal, periodical, yearbook, biletin, annual review, dan recent advances (Nazir, 2011). Sumber bacaan dalam penelitian ini adalah jurnal ilmiah. Data yang diperoleh dalam penelitian ini adalah data kuantitatif dan kualitatif. Teknik analisis data menggunakan analisis data isi.

\section{Hasil dan Pembahasan}

Berdasarkan hasil studi literatur diperoleh beberapa permasalahan dari pembelajaran IPA. Salah satu tujuan utama pembelajaran IPA adalah terwujudnya masyarakat berliterasi sains (Norris \& Phillips, 2003). Literasi sains siswa Indonesia berdasarkan hasil PISA (Programme for International Student Assessment) yang mengukur kemampuan anak-anak usia 15 tahun dalam mengimplementasikan masalah-masalah di kehidupan nyata masih jauh dari harapan. Laporan OECD menunjukkan bahwa literasi sains siswa Indonesia masih rendah yaitu pada tahun 2006 berada diurutan ke 53 (dari 57 negara), tahun 2009 urutan ke 38 (dari 40 negara), dan tahun 2012 urutan 64 (dari 65 negara). Berdasarkan hasil tersebut, Indonesia melakukan reformasi pendidikan untuk mewujudkan siswa yang berliterasi sains dengan mengimplementasikan kurikulum 2013 yang proses pembelajarannya menekankan penggunaan pendekatan ilmiah (Rahayu, 2014). 
Pendekatan ilmiah (scientific approach) merupakan pendekatan sistematis yang terdiri dari keterampilan proses sains seperti mengamati, menginferensi, memprediksi, menanya, menafsirkan dan menganalisis data dengan materi pelajaran, penalaran ilmiah, dan berpikir kritis untuk mengembangkan ilmu pengetahuan (Lederman, Lederman, \& Antink, 2013). Pendekatan ilmiah merupakan pembelajaran yang mengadopsi langkah-langkah ilmuwan dalam membangun pengetahuan melalui metode ilmiah (Rosana, 2014). Dalam Permendikbud No 81A tahun 2013, proses pembelajaran dengan pendekatan ilmiah terdiri dari lima pengalaman belajar, yaitu: (a) mengamati; (b) menanya; (c) mengumpulkan informasi; (d) mengasosiasi; dan (e) mengkomunikasikan. Pembelajaran dengan menggunakan pendekatan ilmiah akan berlangsung secara efektif apabila disertai dengan pengeksplisitan hakikat sains (Nature of Science, NOS) (Wenning, 2006; Lederman, 2006; Paraskevopoulou \& Koliopoulos, 2011).

Hakikat sains merupakan suatu multikonsep yang meliputi aspek sejarah, sosiologi, dan filosofi sains yang sering didefinisikan sebagai epistimologi sains, karakteristik pengetahuan saintifik, dan sains sumber pengetahuan (Bell, 2009). Hakikat sains mencakup konsepsi tentang pengetahuan sains, nilai-nilai dan keyakinan dalam memperoleh pengetahuan sains serta pengaruhnya terhadap masyarakat, budaya, dan teknologi. Hakikat sains yang diajarkan secara eksplisit dapat meningkatkan hasil belajar tentang materi sains, minat belajar sains, dan pengambilan keputusan terhadap masalah-masalah yang berhubungan dengan sains (Lederman, 2006; Bell, Matkins, \& Gansneder, 2011). Hakikat sains dapat dieksplisitkan dalam kurikulum/standar, proses pembelajaran di kelas maupun dalam bahan ajar (Rahayu, 2014).

Bahan ajar merupakan salah satu sumber belajar yang penting dalam pelaksanaan pembelajaran di sekolah (Depdiknas, 2008). Bahan ajar dapat memfasilitasi siswa untuk mengkonstruk pengetahuan sesuai langkah pembelajaran dan mengembangkan pengetahuan siswa melalui konten materi yang lebih kontekstual dalam kehidupan sehari-hari (Mahanani, 2014). Analisis terhadap buku SMP IPA Biologi dijelaskan bahwa secara umum buku teks IPA SMP lebih banyak menyajikan teori dan hukum dalam sains (67\%) dan kurang menyajikan komponen hakikat sains yang lain, sehingga aspek sains yang diperoleh siswa kurang (Aulia dkk, 2014). Penelitian lain menunjukkan bahwa buku teks yang digunakan dalam pembelajaran IPA Kimia di Kota Malang belum mencerminkan hakikat sains secara maksimal yaitu hanya sebesar 23,87\% (Handoko, 2012). Hasil penelitian tersebut menunjukkan bahwa bahan ajar IPA yang ada belum mencerminkan hakikat sains secara maksimal kepada siswa.

Penelitian mengenai pemahaman NOS siswa SMP terbaik se-Jawa Timur oleh Rahayu (2016) menunjukkan bahwa dari 840 siswa yang disampling hanya 8\% siswa yang paham terhadap aspek NOS. Penelitian yang sama terhadap 93 mahasiswa calon guru IPA Kimia UM menunjukkan bahwa mahasiswa memiliki pemahaman yang cukup baik $(60,73 \%)$, namun kurang bagus $(15,40 \%)$ pada aspek teori ilmiah. Hal ini menunjukkan bahwa mahasiswa calon guru IPA Kimia UM sudah memahami NOS dengan cukup baik walaupun masih perlu mendapatkan penekanan pada beberapa aspek NOS tersebut. Berdasarkan penelitian tersebut, diperlukan adanya bahan ajar IPA menggunakan pendekatan ilmiah dengan mengeksplisitkan hakikat sains yang diharapkan dapat mengembangkan kemampuan literasi sains siswa. 
Sejalan dengan hal tersebut diatas, kemampuan literasi sains siswa dalam mengkonstruk pengetahuan melalui pendekatan ilmiah dengan disertai pengeksplisitan hakikat sains dapat ditingkatkan melalui keterampilan berpikir kritis (Lederman, Lederman, \& Antink, 2013; Mahanani, 2014). Berpikir kritis adalah pemikiran reflektif yang masuk akal yang berfokus pada pengambilan keputusan tentang apa yang harus dipercaya atau dilakukan (Ennis, 2011). Berpikir kritis merupakan salah satu jenis dari HOTS (Higher Order Thinking Skills). Dalam beberapa dekade berpikir kritis merupakan salah satu tujuan dari pendidikan sains (Ennis, 1993). Siswa yang terbiasa menggunakan keterampilan berpikir kritis akan lebih mudah dalam memperoleh ilmu pengetahuan dan menerapkannya dalam kehidupan sehari-hari (Bell et al., 2000; Mahanani, 2014).

Salah satu materi dalam IPA yang berhubungan dengan kehidupan sehari-hari adalah topik energi dalam sistem kehidupan. Topik energi dalam sistem kehidupan pada kelas VII semester 2 dalam kurikulum 2013 membahas mengenai konsep energi, berbagai sumber energi, energi dari makanan, transformasi energi dalam sel, metabolisme sel, respirasi, sistem pencernaan makanan, dan fotosintesis. Topik energi termasuk konsep yang sulit dimengerti oleh siswa karena bersifat abstrak dan kompleks, seperti fotosintesis dan respirasi (Ross et al, 2005; Hershey, 2004; Cokadar, 2012). Topik energi dalam sistem kehidupan juga masuk dalam dimensi konten dan aplikasi bidang teknologi dalam tes PISA yang digunakan untuk menilai literasi sains siswa.

Berdasarkan uraian di atas, maka kebutuhan bahan ajar IPA SMP dengan mengeksplisitkan hakikat sains (NOS) dan berpikir kritis topik energi dalam sistem kehidupan sangat diperlukan dalam pembelajaran. Bahan ajar yang mampu mengembangkan literasi sains siswa adalah bahan ajar yang memuat aspek-aspek terkait literasi sains yaitu dengan mengeksplisitkan hakikat sains (NOS) dan memasukkan soal-soal berpikir kritis. Bahan ajar dapat membantu siswa untuk menganalisis permasalahan yang terjadi di lingkungan sekitar dan menentukan solusi pemecahan masalah tersebut dengan membuat keputusan yang bertanggungjawab.

\section{Simpulan}

\subsection{Kesimpulan}

Berdasarkan hasil studi literatur, dapat disimpulkan bahwa perlu dikembangkan bahan ajar IPA SMP dengan mengeksplisitkan hakikat sains (NOS) dan berpikir kritis topik energi dalam sistem kehidupan. Bahan ajar harus sesuai dengan tujuan utama pembelajaran IPA yaitu mengembangkan literasi sains.

\subsection{Saran}

Saran diperlukan untuk menindaklanjuti penelitian. Saran untuk penelitian selanjutnya adalah melakukan pengembangan bahan ajar IPA SMP pada topik energi dalam sistem kehidupan. Pengembangan seharusnya mengeksplisitkan aspek-aspek yang terkait dengan literasi sains yaitu hakikat sains (NOS) dan memasukkan soalsoal berpikir kritis. 


\section{Daftar Rujukan}

Aulia, A.N., Adisendjaja, Y.H, \& Priyandoko, D.. (2014). Analisis buku teks biologi smp di kota bandung berdasarkan hakikat sains . Formica Education, 1 (1): 1-15.

Bell, R. L. (2009). Teaching the nature of science: Three critical questions. Best Practices in Science Education, 22, 1-6.

Bell, R. L., Matkins, J. J., \& Gansneder, B. M. (2011). Impacts of contextual and explicit instruction on preservice elementary teachers' understandings of the nature of science. Journal of Research in Science Teaching, 48(4), 414-436.

Bell, R. L., Lederman, N. G., \& Abd-El-Khalick, F. (2000). Developing and acting upon one's conception of the nature of science: A follow-up study. Journal of Research in Science Teaching: The Official Journal of the National Association for Research in Science Teaching, 37(6), 563-581.

Cokadar, H. (2012). Photosynthesis and Respiration Processes: Prospective Teachers' Conception Levels. Education \& Science/Egitim ve Bilim, 37(164).

Ennis, R. H. (1993). Critical Thinking Assessment. Columbus: The Ohio State University.

Ennis, R. H. (2011). The nature of critical thinking: An outline of critical thinking dispositions and abilities. University of Illinois, 2(4).

Handoko, E. A. (2012). Analisis hakikat sains (the nature of science) dalam buku teks pelajaran kimia SMA kelas XI (Doctoral dissertation, Universitas Negeri Malang).

Hershey, D. R. (2004). Avoid misconceptions when teaching about plants. Website

Holbrook, J., \& Rannikmae, M. (2009). The meaning of scientific literacy. International Journal of Environmental and Science Education, 4(3), 275-288.

Kebudayaan, K. P. (2013). Materi Pelatihan Guru Implementasi Kurikulum 2013. Nuh, M.(2013). Kurikulum.

Kementerian Pendidikan dan Kebudayaan, M. P. (2013). Permendikbud No 81 A. Tahun 2013 tentang Implementasi Kurikulum.

Lederman, N. G. (2006, June). Research on nature of science: reflections on the past, anticipations of the future. In Asia-Pacific Forum on Science Learning and Teaching (Vol. 7, No. 1, pp. 1-11). The Education University of Hong Kong, Department of Science and Environmental Studies.

Lederman, N. G., Lederman, J. S., \& Antink, A. (2013). Nature of science and scientific inquiry as contexts for the learning of science and achievement of scientific literacy. International Journal of Education in Mathematics, Science and Technology, 1(3).

Mahanani, I. (2020). Pengembangan bahan ajar materi reaksi redoks dan elektrokimia menggunakan pendekatan saintifik dengan mengeksplisitkan hakikat sains (NOS) dan berpikir kritis. SKRIPSI Mahasiswa UM.

Nazir, M. (2011). Metode Penelitian, Cetakan Ke Tujuh. Bogor: Penerbit Ghalia Indonesia.

Norris, S. P., \& Phillips, L. M. (2003). How literacy in its fundamental sense is central to scientific literacy. Science education, 87(2), 224-240.

Organization for Economic Cooperation and Development (OECD). (2010). The Example of PISA Questions. Take The Test: Sample Questions From OECD's PISA Assessments. Website http://www.oecd.org/pisa [accessed 7 September 2015].

Paraskevopoulou, E., \& Koliopoulos, D. (2011). Teaching the nature of science through the Millikan-Ehrenhaft dispute. Science \& Education, 20(10), 943-960.

Rahayu, S. (2014). Menuju masyarakat berliterasi sains: Harapan dan tantangan kurikulum 2013. In Seminar Nasional Kimia dan Pembelajarannya (pp. 27-40).

Rahayu, S. (2016). Mengembangkan literasi sains anak indonesia melalui pembelajaran berorientasi nature of science (NOS). Makalah disajikan dalam Pidato Pengukuhan Jabatan Guru Besar Universitas Negeri Malang, Malang, 17.

Rosana, D. (2014). Pendekatan saintifik dalam pembelajaran IPA secara terpadu. In Seminar Nasional Unnes (pp. 4-21).

Ross, P. A., Tronson, D., \& Ritchie, R. A. J. (2006). Modelling photosynthesis to increase conceptual understanding. Journal of Biological Education, 40(2), 84-88. 
Tinggi, D. J. P. Departemen Pendidikan Nasional (Depdiknas).(2008). Hasil Evaluasi Sistem Penjaminan Mutu Internal Perguruan Tinggi Tahun 2008.

Ulfatin, N. (2013). Metode penelitian kualitatif di bidang pendidikan: teori dan aplikasinya: studi kasus, etnografi, interaksi simbolik, dan penelitian tindakan pada konteks manajemen pendidikan. Malang: FIP Universitas Negeri Malang.

Wenning, C. J. (2006). A framework for teaching the nature of science. Journal of Physics Teacher Education Online, 3(3), 3-10.

Wenning, C. J. (2010). Science Literacy: What It Is, How to Assess It, and A Way to Achieve It. Website http://www.phy.ilstu.edu/pte/INDONESIA/PDFs/G.\%20SciLit-What_\%26_How.pdf [accessed 28 Agustus 2015].

Yuliati, L. (2008). Model-model Pembelajaran Fisika: Teori dan Praktek. Malang: LP3 Universitas Negeri Malang. 